\title{
Isolation and Identification of Extended-Spectrum Beta-Lactamases Producing $E$. coli and Klebsiella from Human
}

\author{
Rajeev Prajapati ${ }^{1}$, Namita Joshi ${ }^{1^{*}}$ and R.K. Joshi ${ }^{2}$
}

${ }^{1}$ Department of Veterinary Public Health \& Epidemiology, College of Veterinary Science \& A.H., N.D. University of Agriculture and Technology, Kumarganj- 224229, Faizabad (UP), India

${ }^{2}$ Department of Veterinary Microbiology, College of Veterinary Science \& A.H., N.D. University of Agriculture and Technology, Kumarganj-224229, Faizabad (UP), India

*Corresponding author

Keywords

ESBL, Klebsiella,

E. coli, urine,

Haemagglutination.

Article Info

Accepted:

05 January 2020

Available Online:

10 February 2020

\section{A B S T R A C T}

The irrational and indiscriminate use of antibiotics has made antibiotic resistance as biggest health problem of India. Therefore, the present study was undertaken with the aim to isolate ESBL producing E. coli and Klebsiella from clinical human cases. A total of 100 urine samples of human were collected from pathology lab of Faizabad and Gorakhpur district and processed for isolation of E. coli and Klebsiella. All isolates were screened for ESBLs production by using Cefotaxim and Ceftazidime disk. The presumptive ESBL producers were further confirmed by combination disk test using ESBL kits and by targeting ESBL genes using PCR technique. The isolation rate of E. coli and Klebsiella was found to be $24 \%$ and $26 \%$ and all were found presumptive ESBL producers on preliminary screening. Further confirmation by combination disk test revealed $41.7 \%$ and $61.5 \%$ prevalence of ESBLs in E. coli and Klebsiella. The molecular study revealed $b l a_{\text {TEM }}$ gene in only one $(10 \%) E$. coli isolate, while $b l a_{\text {СтХ-м }}$ gene was prevalent in $70 \%$ E. coli isolates and $93.75 \%$ Klebsiella isolates. Conclusions: The present study showed predominance of bla $a_{\text {СтХ-м }}$ gene in both E. coli and Klebsiella which indicates irrational use of antibiotics in human medicine posing a great risk to the health of both human and animal population.

\section{Introduction}

Antimicrobial resistance has become a most common problem in both human and veterinary medicine across the world. Currently, one of the most important resistance mechanisms in Enterobacteriaceae, which reduces the efficacy even of modern expanded-spectrum cephalosporins and monobactams, is mediated by extendedspectrum beta-lactamases (ESBLs) (Bonnet, 2004). ESBL are beta-lactamases capable of 
conferring bacterial resistance to the penicillins; first-, second- and thirdgeneration cephalosporins; and aztreonam (but not the cephamycins or carbapenems) and which are inhibited by beta-lactamase inhibitors such as clavulanic acid, sulbactam, and tazobactam (Paterson and Bonomo, 2005).

The incidence of ESBL producing strains among clinical isolates has been steadily increasing over the past years, resulting in limitation of therapeutic options. Therefore, present study was undertaken to know the ESBL status in human population, as no such study has been done previously in this area.

\section{Materials and Methods}

\section{Sample Collection}

A total of 100 urine samples of clinical human cases were collected from pathology labs of Faizabad and Gorakhpur districts of Uttar Pradesh in sterilized vials and brought to the laboratory under refrigerated condition.

Isolation and identification of $E$. coli and Klebsiella

The samples were processed for isolation of E. coli and Klebsiella using the method described by Cruickshank et al., (1975). The identification of E. coli and Klebsiella isolates was done on the basis of morphology, growth, biochemical characteristics as per the procedure of Edwards and Ewing (1972).

\section{Identification of ESBL producers}

The isolates identified as E. coli and Klebsiella were subjected to disk diffusion test for screening using cefotaxim and ceftazidime disks prescribed in CLSI guideline (2009). The test organisms were presumed as ESBL producers if the zone diameter for cefotaxim was $\leq 27 \mathrm{~mm}$ and for ceftazidime $\leq 22 \mathrm{~mm}$. Phenotypic confirmation was done by double disks synergy test using ESBL kit 1 and kit 3 (Hi media).

The test organisms were considered as ESBL positive if $\mathrm{a} \geq 5 \mathrm{~mm}$ increase in zone diameter was observed for two or more antimicrobial agents tested in combination with clavulanic acid versus its zone when tested alone.

\section{Molecular characterization of ESBL producers}

The ESBL genes $b l a_{\text {TEM }}$ and $b l a_{\text {CTX-M }}$ were targeted for molecular identification of ESBL. The DNA templates were prepared using snap- chill method as described by Franco et al., (2008). The primer sequence F-ATGAGT ATTCAACATTTCCG and R-TTAATCAGT GAGGCACCTAT for bla $a_{\text {TEM }}$ (Grimm et al., 2004) and F-CGCTTTGCGATGTGCAG and R-ACCGCGATATCGTTGGT for $b l a_{\mathrm{CTX}-\mathrm{M}}$ (Paterson et al., 2003) synthesized by Bangalore Genei (India) were used.

The PCR assay for $b l a_{\text {TEM }}$ was standardized as per the procedure described by Grimm et al., (2004). The amplification of bla $a_{\mathrm{TEM}}$ was conducted in final volume of $20 \mu$ l containing $0.4 \mu \mathrm{l}$ of dNTP $(50 \mu \mathrm{M}) \mathrm{mix}, 1 \mu \mathrm{l}$ of forward and reverse primer (100pmol), $0.2 \mu \mathrm{l}$ of taq polymerase (1U), $2 \mu \mathrm{l}$ of $\mathrm{MgCl}_{2},(2.5 \mathrm{mM}), 2 \mu \mathrm{l}$ of DNA template and $13.4 \mu \mathrm{l}$ of nuclease free water.

The PCR cycling condition included initial denaturation at $95^{\circ} \mathrm{C}$ for $5 \mathrm{~min}$ followed by 35 cycles at $94^{\circ} \mathrm{C}$ for $30 \mathrm{sec}$, annealing at $50^{\circ} \mathrm{C}$ for $35 \mathrm{sec}$, elongation at $72^{0} \mathrm{C}$ for $40 \mathrm{sec}$ and final extension at $72^{\circ} \mathrm{C}$ for $5 \mathrm{~min}$. However, the amplification of bla $a_{\text {CTX-M gene was }}$ conducted as per the procedure described by Paterson et al., (2003) with slight 
modification. The PCR mix composition and cycling conditions were same as for bla $a_{\mathrm{TEM}}$ except the primer concentration and annealing temperature.

The primer concentration was $48 \mathrm{pmol}$ for forward and 54pmol for reverse primer, volume $2 \mu \mathrm{l}$ each while annealing temperature was $55^{\circ} \mathrm{C}$.The amplified PCR products were run in $1.5 \%$ agarose gel and visualized and analyzed under gel documentation system (Uvi tech, UK).

\section{Haemagglutination Assay}

ESBL positive isolates were also screened for mannose resistant haemagglutination (MRHA) and mannose sensitive haemagglutination (MSHA) property by using the method of Green and Thomas (1981) with slight modification. The isolates sub- cultured in nutrient broth for $24 \mathrm{hrs}$ at $37^{\circ} \mathrm{C}$ were centrifuged at $10,000 \mathrm{rpm}$ for $10 \mathrm{~min}$.

The pellet so obtained was washed in phosphate buffer saline and cell concentration was adjusted to approximately $2 \times 10^{10}$ $\mathrm{CFU} / \mathrm{ml}$ by the McFarland turbidimetric method. The 2\% (W/V) D (+) mannose solution was then mixed with equal amount of 5\% sheep RBCs suspension and kept for few min at $4^{\circ} \mathrm{C}$ before its use to demonstrate mannose sensitive haemagglutination.

Fifty microliter of bacterial suspension was emulsified in equal amount of PBS at two spots on a microscopic slide. Then, fifty microliter of 5\% RBC suspension with and without mannose was added on these spots. The contents were mixed thoroughly by rotating the slide gently in circular manner.

The isolates showing clumping of RBCs without mannose were considered as HA positive. However, clumping of RBCs mixed with mannose was regarded as mannose resistant haemagglutination (MRHA) and absence of clumping at the same spot was considered as mannose sensitive haemagglutination (MSHA). The suspension of RBCs with and without mannose in PBS was taken as negative control.

\section{Results and Discussion}

In India, there is irrational and indiscriminate use of antibiotics in human and veterinary practices. Therefore, extended-spectrum betalactamase (ESBL) producing Enterobacteriaceae has become widespread in hospitals and is spreading increasingly in community settings where they cause a variety of infections (Maina et al., 2013).

Keeping in view above, the present study was undertaken with the aim to know status of ESBL producing E. coli and Klebsiella spp in this area. Overall 95 isolates were recovered out of 100 urine sample collected from clinical human cases but based on growth, staining and biochemical characteristics, merely 24 and 26 isolates could be identified as E. coli and Klebsiella (Table1).

Table.1 Occurrence of ESBL, MRHA and MSHA among E. coli and Klebsiella isolates

\begin{tabular}{|c|c|c|c|c|c|}
\hline S. No. & $\begin{array}{c}\text { Name of } \\
\text { Organism }\end{array}$ & $\begin{array}{c}\text { No. of } \\
\text { isolates }\end{array}$ & $\begin{array}{c}\text { ESBL positive } \\
\text { isolates }\end{array}$ & MRHA positive & MSHA positive \\
\hline 1. & E. coli & 24 & 10 & $3(12.5)$ & No. $(\%)$ \\
\hline 2. & Klebsiella & 26 & 16 & $6(23.07)$ & $10(76.93)$ \\
\hline
\end{tabular}


The isolates grew luxuriantly and selectively on MLA showing rose pink color, a characteristic of lactose fermenter although Klebsiella colonies were light pink and mucoid in appearance. The tiny metallic sheen colonies on EMB were considered as $E$. coli, while purple dark centered colonies with mucoid rim were regarded as Klebsiella.

Comparatively low isolation rate in this study may be ascribed to the source of samples that were from the patients having undergone prolong antibiotic treatment. Similar finding were reported by Rajan and Prabavathy (2012) from Chennai as they found only 20.46 percent cultures positive for $E$. coli out of 562 urine samples suspicious of UTI.

Likewise, Ravichitra et al., (2014) reported low (26 percent) isolation rate of Klebsiella spp. from urine sample, which was similar to our finding. Manjula et al., (2014) could also isolate only 19.9 percent Klebsiella from urine sample of pregnant women from Karnataka (India).

Identification of ESBL producers among $E$. coli and Klebsiella isolates was done by screening test followed by phenotypic confirmatory test (Fig1).

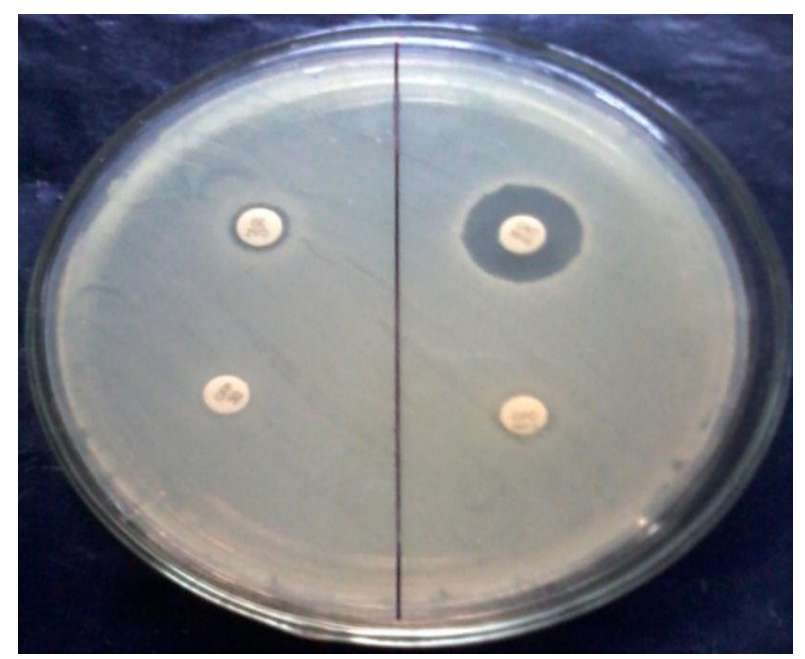

Fig.1 Phenotypic Confirmatory Test for ESBLs
On preliminary screening, all isolates of $E$. coli $(100 \%)$ and Klebsiella $(100 \%)$ were presumed to be ESBL producers as per CLSI recommendations (Wayne, 2009).

Since the affinity of ESBLs for different substrates is variable, the use of more than one antimicrobial agent for screening improved the sensitivity of detection (Wayne, 2009).

By phenotypic confirmation method, the potential ESBL producers in $E$. coli and Klebsiella spp. were found to be $41.67 \%$ and $61.54 \%$, respectively (Table 1 ).

Similar findings have earlier been reported from Karnataka (Rao, et al., 2014), Tamilnadu (Thenmozhi and Sureshkumar, 2013) and Sikkim (Tsering, et al., 2009) and other parts of India.

Over the last two decades, the incidence of infection caused by multidrug resistance Klebsiella strain has increased (Morgan et al., 1984). In a study from Delhi, 68\% of Gram negative bacteria were found to be ESBL producers, with $80 \%$ of Klebsiella being ESBL producers (Mathur et al., 2002).

In this study too, the frequency of ESBL producer was higher in Klebsiella isolates rather than $E$. coli isolates. Thus in most of the studies, Klebsiella pneumoniae is more often reported as major ESBL producer (Gupta et al., 2002; Gales et al., 2002; Akata et al., 2003).

The molecular study of all ESBL producing $E$. coli isolate $(10 \%)$ revealed only one bla $a_{\mathrm{TEM}}$ gene (Fig 2). However, the prevalence of

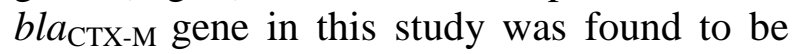
$70 \%$ and $93.75 \%$ in E. coli and Klebsiella isolates, respectively (Table 2). Almost, all the Klebsiella isolates harboured bla $_{\mathrm{CTX-M}}$ gene (Fig 3) 
Our finding coincided with previous studies, because since 2000, the CTX-M enzymes have formed a rapidly growing family of $u$ cephalosporins especially ceftriaxone and cefotaxime or may be associated with high mobilization of the encoding genes (Barguigua et al., 2011).

Barlow et al., (2008) also reported that the $b l a_{\text {CTX-M }}$ gene have been mobilized to plasmid almost 10 times more frequently than other class A beta-lactamases.

The present study also indicated the predominance of CTX-M gene in this region of UP (Fig 4). A phenotypic assay was also conducted to determine the virulence of ESBL positive isolates. The ability to cause agglutination of erythrocytes is an indirect evidence of presence of fimbriae and can be used as a simple indirect method of virulence testing (Tabasi et al., 2015).

In present study, out of 24 E. coli, 3 (12.5 percent) isolates showed haemagglutination with sheep erythrocytes of which all were MRHA positive. In case of Klebsiella isolates, 09 out of 26(34.61 percent) showed hemagglutination of which 6 (23.08 percent) isolates were MRHA positive and 3 (11.54 percent) isolates were MSHA positive.

Table.2 ESBL gene distribution among E. coli and Klebsiella isolates

\begin{tabular}{|c|c|c|c|}
\hline S. No. & Bla gene & $\boldsymbol{E}$. coli $(\boldsymbol{\%})$ & Klebsiella $(\%)$ \\
\hline $\mathbf{1}$ & TEM & $1(10)$ & None \\
\hline $\mathbf{2}$ & CTX-m & $7(70)$ & $15(93.75)$ \\
\hline $\mathbf{3}$ & TEM and CTX-m & $1(10)$ & None \\
\hline $\mathbf{4}$ & Non TEM and non & $1(10)$ & $1(6.25)$ \\
\hline
\end{tabular}

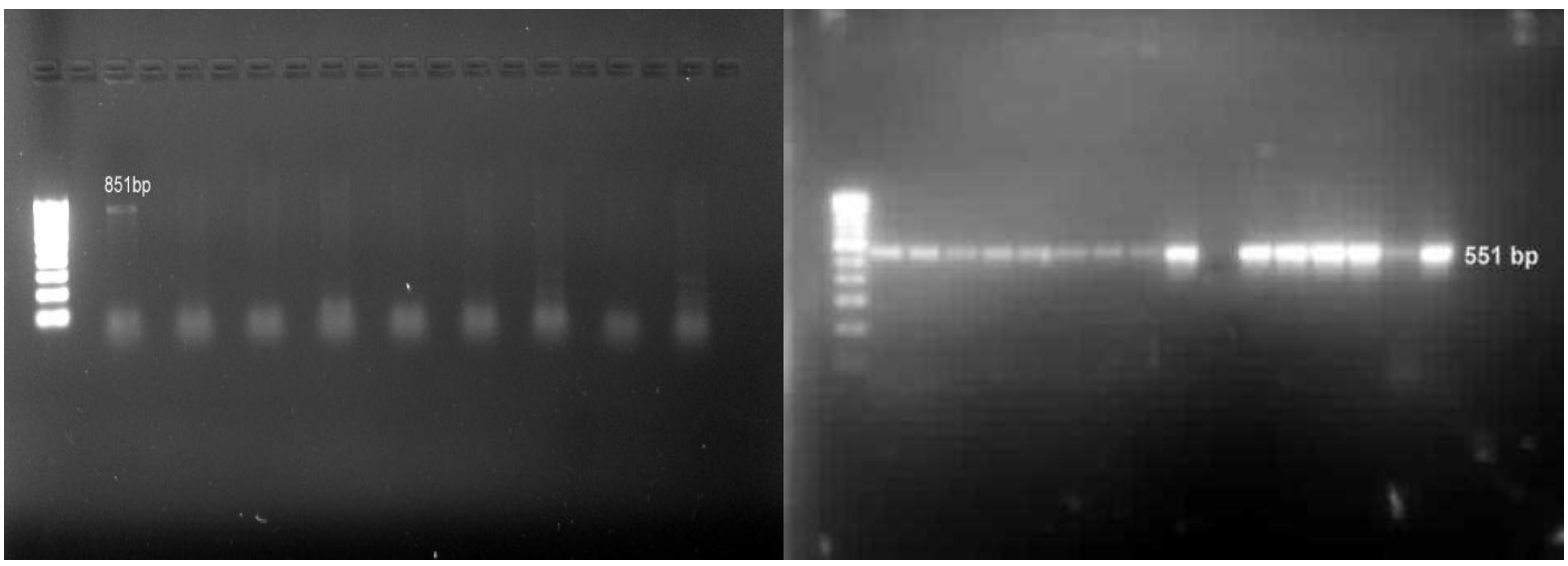

Fig.2 bla TEMgene $(851 \mathrm{bp})$

Fig.3 bla $_{\text {CTX-M }}$ gene $(551 \mathrm{bp})$ 


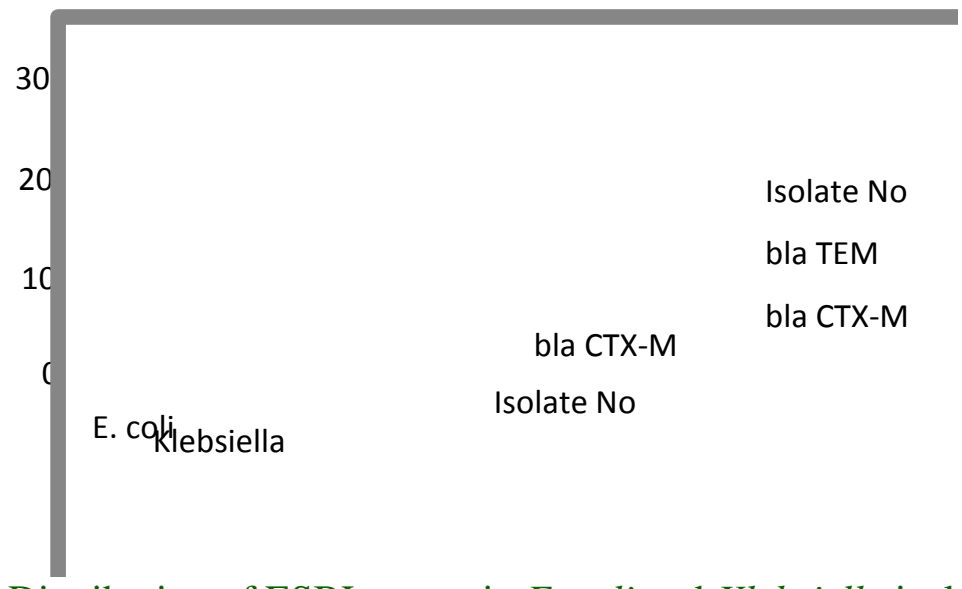

Fig.4 Distribution of ESBL genes in E. coli and Klebsiella isolates

Rest isolates were negative for haemagglutination with sheep erythrocytes (Table-1). The findings were in agreement with observation of Tabasi et al., (2015) although degree of haemagglutination has been reported to differ with erythrocytes of different origin.

The studies have shown that $\mathrm{P}$ fimbriae encoded by pap (pyelonephritis-associated pilus) operon are the most important mannose-resistant adhesions, although they are expressed by only a limited number of $E$. coli serotypes as evident from present study (Jadhav, 2011).

The isolates showing MSHA property might be having type 1 fimbrae that are Mannose sensitive adhesions present in many strain of E. coli including non-pathogenic one (Jadhav, 2011). Strains with MRHA property may be regarded as uropathogenic as they have been reported to attach in higher number to human urinary tract epithelial cells (Hagberg et al., 1981).

\section{Acknowledgement}

The author is thankful to College of Veterinary Sciences and A.H., N.D. University of Agriculture and Technology,
Kumarganj, Faizabad (U.P.) for providing facilities to conduct the experiment.

\section{References}

Akata, F., Tatman-Otkum, M., Ozkan E., Tansel, O., Otkum, M., and Tugrul, M. 2003. Prevalence of extended spectrum beta lactamases produced by nosocomial isolate of enterobacteriaceae in Trakta University hospital,Turkey. New Microbiol. 26: 257-262.

Barguigua, A., El, Otmani F., Talmi, M., Bourjilat F., Haouzane, F., Zerouali, K. and Timinouni, M.2011. Characterization of ESBL-producing $E$. coli and Klebsiella pneumoniae isolates from community in Morocco. J Med Microbiol; 60: 1344-1352.

Barlow, M.; Reik, R.A.; Jacobs, S.D.; Medina, M. and Meyer, M.P. 2008. High rate of mobilization for CTX-M. Emerg Infect Dis. 14: 423-428.

Bonnet, R. 2004. Growing group of extendedspectrum beta-lactamases: the CTX-M enzymes. Antimicrob Agents Chemother. 48: 01-14.

Cruickshank, R., Duguid, J.P., Marmion, B.P. and Ewing, W.H. 1975. Identification of Enterobacteriacae, $3^{\text {rd }}$ ed. (Burges 
Publishing co. Atlanta, Georgia, U.S.A.) 152-154.

Edwards, P.R. and Ewing, W.H. 1972. Identification of Enterobacteriaceae, $3^{\text {rd }}$ ed. (Minneapolis: Burgess Publishing Co. Atlanta, Georgia, U.S.A.) 290.

Franco, S., Murphy, M. M., Li, G., Borjeson, T., Boboila C. and Alt, F.W. 2008. DNA-PKcs and Artemis function in the end-joining phase of immunoglobulin heavy chain class switch recombination. J. Exp. Med. 205: 557-564.

Gales, A.C., Sader, H.S., and Jones, R.N. 2002. Urinary tract infection trends in Latin American hospitals: report from the SENTRY antimicrobial surveillance program. Diagn Microbiol Infect Dis.; 44: 289-299.

Green, C. P. and Thomas V. L. 1981. Hemagglutination of human type $\mathrm{O}$ erythrocytes, hemolysin production, and serogrouping of $E$. coli isolates from patients with acute pyelonephritis, cyctitis and asyptomatic bacteriuria. Infect Immun. 31(1):309-315.

Grimm, V., Ezaki, S., Susa, M., Knabbe, C., Schmid, R.D. and Bachmann, T.T. 2004. Use of DNA Microarrays for Rapid Genotyping of TEM BetaLactamases that Confer Resistance. J Clin Microbiol. 42: 3766-3774.

Gupta, A.; San Gabriel, P. and Haas, J. 2002. Extended spectrum beta-lactamase (ESBL) producing Klebsiella pneumoniae outbreak in a neonatal intensive care unit (NICU). Abstract 241. In: 12th Annual Scientific Meeting of Society for Healthcare Epidemiology of America (SHEA), Salt Lake City, Utah.

Hagberg L., Jodal, U., Korhonen, T.K., LidinJanson, G., Lindberg, U. and Svanborg Eden, C. 1981. Adhesion, Haemagglutination and Virulence of $E$. coli causing urinary tract infections. Infect Immun. 31: 564-570.
Jadhav, S.; Hussain, A.; Devi, S.; Kumar, A.; Parveen, S; Gandham, N.; Wieler, L. H.; Ewers, C. and Ahmed, N. 2011. Virulence Characteristics and Genetic Affinities of Multiple Drug Resistant Uropathogenic $E$. coli from a Semi Urban Locality in India. PLoS One. 6(3): 18063.

Livermore, D.M., Canton, R. and Gniadkowski, M. 2007. CTX-M: changing the face of ESBLs in Europe. J Antimicrob Chemoth.; 59: 165-174.

Maina, D., Makau, P., Nyerere, A. and Revathi, G. 2013. Antimicrobial resistance patterns in extendedspectrum $\beta$-lactamase producing $E$. coli and Klebsiella pneumoniae isolates in a private tertiary hospital, Kenya. Microbiol Discovery.1: 1-4.

Manjula, N.G., Math, C.C., Naqshetty, K., Patil, S. A., Gaddad, S.M. and Shivannavar, C.T. 2014. Antibiotic Susceptibility Pattern of ESBL Producing Klebsiella pneumoniae Isolated from Urine Samples of Pregnant Women in Karnataka. J Clin Diagn Res. 8: 08-11.

Mathur, P.; Kapil, A.; Das, B. and Dhawan, B. 2002. Prevalence of extended spectrum $\beta$-lactamase producing gram negative bacteria in a tertiary care hospital. Indian J Med Res. 115: 153157.

Morgan, M.E., Hart, C.A. and Cooke, R.W. 1984. Klebsiella infection in a neonatal intensive care unit: role of bacteriological surveillance. J Hosp Infect. 5: 377-385.

Mshana, S.E. and Imirzalioglu, C. 2009. Conjugative IncFI plasmids carrying CTX-M-15 among E. coli ESBL producing isolates at a University hospital in Germany. BMC Infect Dis. 9:97.

Paterson, D. and Bonomo R. 2005. Extended spectrum beta lactamase: A clinical 
update. Clinical Microbiology Reviews. 18: 657-686.

Paterson, D.L., Hujer, K.M., Hujer, A.M., Yeiser, B., Bonomo, M.D., Rice, L.B. and Bonomo, R.A. 2003. Extended spectrum $\beta$-lactamase in Klebsiella pneumoniae bloodstream isolates from seven countries: Dominance widespread prevalence of SHV, CTX-M-type $\beta$ lactamase. Antimicrob. Agents Chemoth. 47: 3554-3560.

Pitout, J.D. and Laupland, KB. 2008. Extended-spectrum beta-lactamaseproducing Enterobacteriaceae: an emerging public-health concern. Lancet Infect. Dis. 8: 159-166.

Rajan, S. and Prabavathy J. 2012. Antibiotic Sensitivity Phenotypic Detection of ESBL producing E Coli Strains Causing Urinary Tract Infection In a Community Hospital, Chennai, Tamil Nadu, India. Pharmaceutical Sci. 3: 38-40.

Rao, S.P.N., Rama, P.S., Gurushanthappa, V., Manipura, R. and Srinivasan K. 2014. Extended-Spectrum Beta-Lactamases Producing E. coli and Klebsiella pneumoniae: A Multi-Centric Study Across Karnataka. J Lab Physicians. 6: 7-13.
Ravichitra, K.N., Prakash, P.H., Subbarayudu, S. and Rao, U.S. 2014. Isolation and antibiotic sensitivity of Klebsiella pneumoniae from pus, sputum and urine samples. Int J Curr Microbiol App Sci. 3: $115-119$

Tabasi, M.; Karam, M. R. A.; Habibi, M.; Yekaninejad, M. S.; Boujari, S. 2015. Phenotypic Assays to Determine Virulence Factors of Uropathogenic Escherichia coli (UPEC) Isolates and their Correlation with Antibiotic Resistance Pattern. Osong Pub Health Res Perspect. 6(4) 261-268.

Thenmozhi, S. and Sureshkumar, B.T. 2013. Prevalence of Extended Spectrum BetaLactamase Producing Gram Negative Bacteria in Private Hospital, Tiruchengode, Tamilnadu, India. Int J Curr Microbiol App Sci.2: 280-289.

Tsering, D.C., Das, S., Adhiakari, L, Pal, R. and Singh, T.S.K. 2009. Extended Spectrum Beta-lactamase Detection in Gram-negative Bacilli of Nosocomial Origin. J Glob Infect Dis. 1: 87-92.

Wayne PA. 2009. Performance Standards for Antimicrobial Susceptibility Testing: Nineteenth Informational Supplement. CLSI document. M100-S19.

\section{How to cite this article:}

Rajeev Prajapati, Namita Joshi and R.K. Joshi. 2020. Isolation and Identification of ExtendedSpectrum Beta-Lactamases Producing E. coli and Klebsiella from Human. Int.J.Curr.Microbiol.App.Sci. 9(02): 357-364. doi: https://doi.org/10.20546/ijcmas.2020.902.045 